\title{
Irritational Pyogenic Granuloma - A Case Report
}

\section{Anamika S*, Vineeta S, Shruti and Shatakshi S \\ Department of Periodontology, Subharti Dental College \& Hospital, India}

*Corresponding author: Anamika Sharma, Professor and Head of Department, Department of Periodontology, Subharti Dental College \& Hospital, Meerut, India, Tel: 09219600994; Email: prof_anamika@hotmail.com

\section{Case Report \\ Volume 2 Issue 3}

Received Date: May 15, 2018

Published Date: June 01, 2018

\section{Abstract}

Gingival overgrowth, results due to increase in the number of cells or cell size. Pyogenic granuloma (PG) a relatively common gingival tumour like over growth, occurs as an exuberant tissue response to localized irritation, trauma or hormonal factors. Because of high incidence of oral PG, critical need arose for its proper diagnosis, management and treatment. This report presents a case of gingival overgrowth which was histo pathologically confirmed to be a pyogenic granuloma. Lesion was excised using diode laser under local anesthesia and proved to be a safe and efficient mode of treatment with minimal post-operative complication. 10 days follow-up showed complete healing by secondary intention and minimal of scaring, with no recurrence following 1 month post operatively.

Keywords: Diode laser; Gingival overgrowth; Pyogenic granuloma

\section{Introduction}

Pyogenic granuloma (granuloma pyogenicum), a distinctive clinical entity originating as a response of the tissue to a non-specific infection, it is a tumor like nonneoplastic growth which occurs as an exaggerated response to minor trauma and invasion of non-specific microorganism. It is characterized as an overzealous proliferation of vascular type of connective tissue. The surface of the lesion may be lobulated and colour may range from pink to red [1]. Management of PG requires removal of Irritational factors as well as excision of gingival overgrowth followed by gingival recontouring. Excisional surgery using conventional method is the best treatment; however other options like use of electro surgery or Laser have also proved to be beneficial.

\section{Case Report}

A male patient aged 46 years reported to the Department of Periodontology, Subharti Dental College and Hospital, Meerut with a chief complaint of gingival overgrowth in lower anterior region present since 15-16 days. Patient had missing 41 and gave history of wearing faulty prosthesis in relation to 41 since last 6 years. Medical history revealed that patient was systemically healthy. Intraoral examination revealed irregularly shaped gingival overgrowth on buccal surface in relation to 31, 32, 33 (Figure 1). Lesion was pedunculated with base connected to the attached gingiva (Figure 2). Lesion was well adapted over the tooth surface and was painless. Therefore, surgical excision using diode laser was planned. 


\section{International Journal of Surgery \& Surgical Techniques}

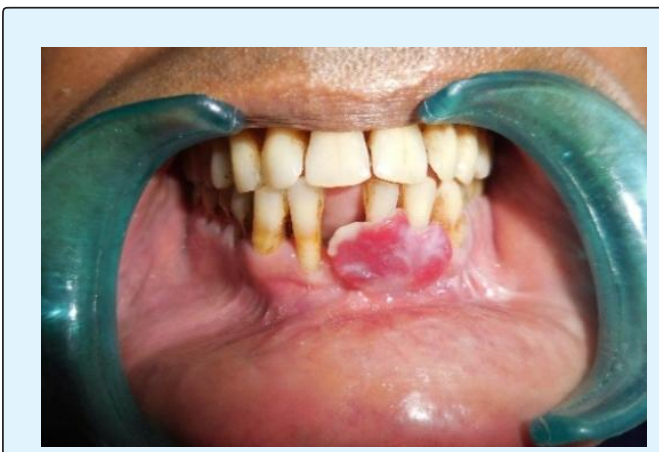

Figure 1: Pre - Operative.

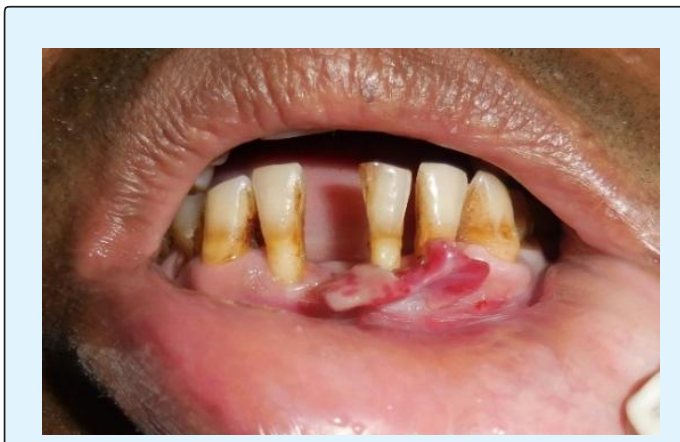

Figure 2: Pedunculated Growth.

\section{Surgical procedure}

Oral prophylaxis was done 2 weeks prior to surgical intervention. After adequate anesthesia of surgical site semiconductor diode laser (gallium-aluminum-arsenide (GaAlAs)) with wavelength $910 \mathrm{~nm}$, output power of 3.5 Watt at non-pulsed mode was used to excise the lesion from the base with the fibre optic tip (200 $\mu$ m diameter) kept perpendicular to the surface (Figure 3). Tip was moved slowly in brush paint like motion. In order to achieve coagulation, the surface of the lesion was carbonized; therefore, there was no need to suture the surgical site (Figure 4). Wound healed with secondary intention.

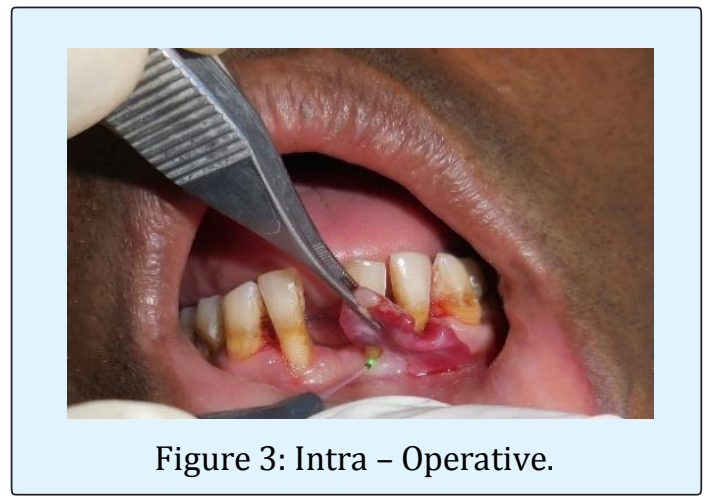

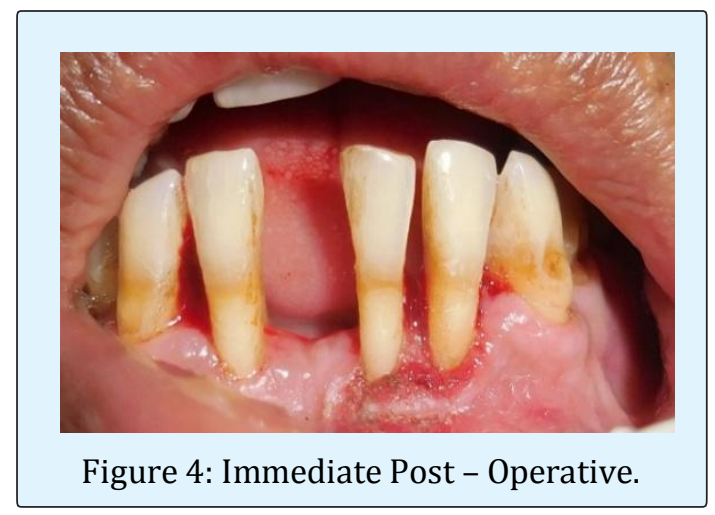

The excised tissue was placed in $10 \%$ formalin solution and sent for histopathologic examination. Patient was given post-surgical instructions and prescribed antibiotics, analgesics for 5 days and recalled after 10 days.

\section{Results}

The excised tissue $15 \times 8 \mathrm{~mm}$ in size (Figure 5), was sent for histopathological evaluation using hematoxylin and eosin stain under 10x magnification where the lesion was confirmed as "pyogenic granuloma" (Figure 6). Patient was followed subsequently for 1 month showing uneventful healing at the surgical site no recurrence (Figure 7).

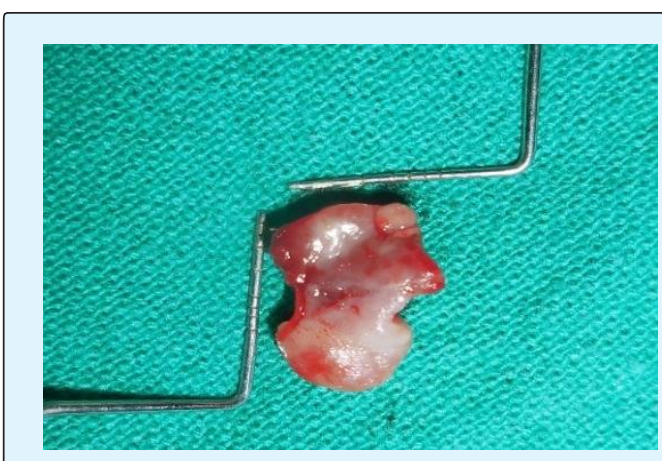

Figure 5: Excised Tissue.

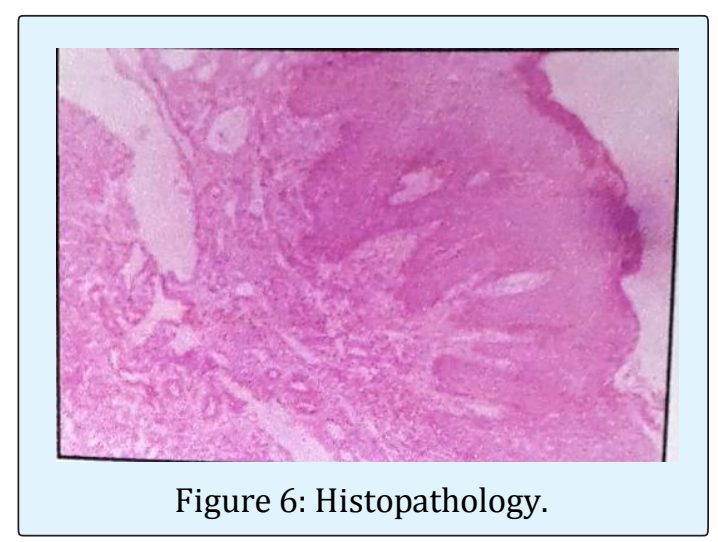




\section{International Journal of Surgery \& Surgical Techniques}

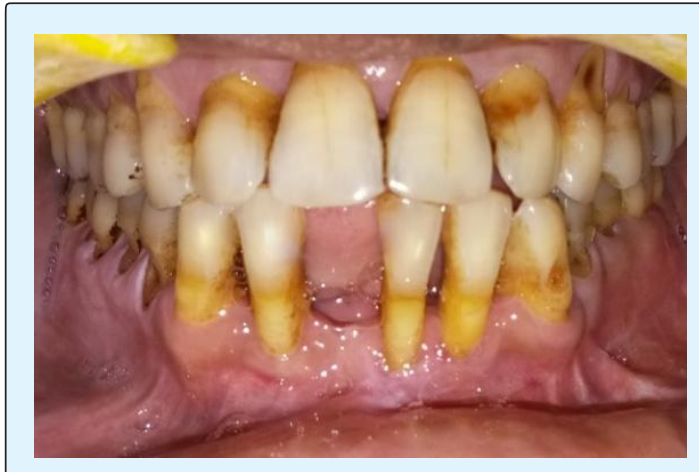

Figure 7: 1 Month Post - Operative.

\section{Discussion}

PG may be seen at any age, and are more common in females than males. PG is prevalent in $75 \%$ of cases, more often in the maxillary than mandibular arch. Anterior areas are more often affected than posterior areas. They can also be found on the lips, tongue, and inner cheek. Poor oral hygiene or trauma is usually precipitating factors [2]. Individuals with poor oral hygiene and chronic oral irritants (eg, overhanging restorations, calculus) most frequently are affected. Pregnancy exacerbates the tendency to develop a PG [3].

Jain, et al. [4] treated a case of irritation fibroma with electrocautery and reported good results with minimal discomfort. Irritation fibroma clinically resembles as pyogenic granuloma, peripheral giant cell granuloma, or odontogenic tumors, so radiographic and histopathological examination is essential for accurate diagnosis. Microscopically $\mathrm{PG}$ is a highly vascular granulation tissue having a fibrotic component if it is older, and the surface may have ulcerations [2]. Prognosis is usually good and recurrence rate of $16 \%$ have been reported. Presence of myxoid structures in the PG may be the main cause of recurrence [3]. However, the present case showed no recurrence even after 1 month.

Singhal, et al. [5] reported a case of Peripheral ossifying fibroma which recurred within 1 week. The recurrent growth was excised, thoroughly curetted, and histo pathologically confirmed as PG. No signs of recurrence were seen at the 6 month follow-up. However, Peripheral ossifying fibroma treated with $980 \mathrm{~nm}$ diode laser reported no history of recurrence in one year [6]. PG is not infectious or malignant, treatment may be considered because of bleeding or ulceration. Frequently, PG is treated with electro surgery (cauterization) and excision by using scalpel, though laser treatment is often effective [7]. Lasers allow efficient execution of soft tissue procedures with excellent Hemostasis and field visibility. When compared to scalpel, electrocautery or high frequency devices, lasers offer maximum postoperative patient comfort [8].

The advantages of laser surgery are minimal swelling, scarring and coagulation, no need for suturing, reduced surgical time with less or no postoperative pain and edema. Also, the laser instantly disinfects the surgical wound and causes no mechanical trauma to the tissue [9]. According to White et al, Laser causes thermal necrosis created by tissue vaporization and protein denaturation, sealing of the ends of sensory nerves, decrease their ability to transmit stimuli and decreasing pain [10].

Mortiz, et al. stated that due to deeper penetration of laser all the immune components like antigen, antibodies, cytotoxic protein and sub-epithelial lymphocyte are denatured. Destruction of the diseased epithelium with its surface antigen causes less risk of edema and the dressing layer of denaturated protein enhances healing leading to less risk of secondary infection [11].

Factors that determine the initial tissue effect of laser are wave length, power, wave form (pulsed or non pulsed type), tissue optical properties and tissue thermal properties [12]. In the present case the fibre optic tip was kept in steady motion and in contact mode, directly over the target tissue. Electrosurgical procedures produce adequate homeostasis but results in greater thermal injury and cause muscle fasciculation and delayed wound healing [13]. However, laser causes minimal change to the adjacent tissue, coagulation and sealing of small vessels and this lead to less post-operative bleeding and excellent healing [14].

\section{Conclusion}

Because of the high incidence of PG there is critical need for its proper diagnosis and management. PG occurring due to local irritation requires removal of irritant as well as surgical excision of lesion. Using diode laser has been proved to be fast, safe and effective method for the excision of oral soft tissue lesion with minimal scarring and complications.

\section{Authorship \& Conflicts of Interest Statement}

\section{Authorship}

All persons who meet authorship criteria are listed as authors, and all authors certify that they have participated sufficiently in the work to take public responsibility for 


\section{International Journal of Surgery \& Surgical Techniques}

the content, including participation in the concept, design, analysis, writing, or revision of the manuscript. Furthermore, each author certifies that this material or similar material has not been and will not be submitted to or published in any other publication.

Authors - 1. Dr. Anamika Sharma
2. Dr.Vineeta Singal
3. Dr. Shruti Panjrath
4. Dr. Shatakshi Sharma

\section{Conflicts of Interest Statement}

The authors whose names are listed immediately below certify that they have NO affiliations with or involvement in any organization or entity with any financial interest (such as honoraria; educational grants; participation in speakers, bureaus; membership, employment, consultancies, stock ownership, or other equity interest; and expert testimony or patent licensing arrangements), or non-financial interest (such as personal or professional relationships, affiliations, knowledge or beliefs) in the subject matter or materials discussed in this manuscript.

Author: 1. Dr. Anamika Sharma
2. Dr.Vineeta Singal
3. Dr. Shruti Panjrath
4. Dr. Shatakshi Sharma

\section{References}

1. Jafarzadeh H, Sanatkhani H, Mohtasham N (2006) Oral pyogenic granuloma: A review. J Oral Sci 48(4): 167-175.

2. Kerr DA (1951) Granuloma Pyogenicum. Oral Surg 4(2): 158-176.

3. Svirsky JA (2016) Oral Pyogenic Granuloma. Medscape drugs and diseases.

4. Jain G, Arora R, Sharma A, Singh R, Aggarwal M (2017) Irritation Fibroma: Report of a case. J Curr Res Sci Med 3(2): 118-121.
5. Singhal A, Arora R, Sharma A (2016) Recurrence of a peripheral ossifuing fibroma as a pyogenic granuloma with in one week: A case report. Clin Adv Periodontol 6(2): 57-60.

6. Sharma A, Sharma V, Kapoor RA, Khattar S, Sharma P (2017) Management of peripheral ossifying fibroma using a $980 \mathrm{~nm}$ diode laser: A one year follow up case report. Int J Curr Res 9(9): 57581-57584.

7. Al-shiaty RA (2015) Recurrent pyogenic granuloma: an update. Int J Sci Reports 1(1): 22-31.

8. Tay YK, Weston WL, Morelli JG (1997) Treatment of pyogenic granuloma in children with the flashlamppumped pulsed dye laser. Pediatrics 99(3): 368-370.

9. Mathur E, Sareen M, Dhaka P, Baghla P (2015) Diode laser excision of oral benign lesions. J Lasers Med Sci 6(3): 129-132.

10. Azma E, Safavi N (2013) Diode Laser Application in Soft Tissue Oral Surgery. J Lasers Med Sci 4(4): 206211.

11. White JM, Goodis HE, Rose CL (1991) Use of pulsed Nd:YAG laser for intra-oral soft tissue surgery. Lasers Surg Med 11(5): 455-561.

12. Mortiz A, Schoop U, Gharkhay K, Wermisch J, Sperr W (1998) Treatment of periodontal pockets with a diode lasers. Laser Surg Med 22(5): 302-311.

13. Gold SI, Vilardi MA (1994) Pulsed laser beam effects on gingival. J Clin Periodontol 21(6): 391-396.

14. Liboonj, Funkhouser W, Terris D (1997) Comparision of musosal incisions made by scalpel, $\mathrm{CO}_{2}$ laser, electro-cautery and constant - voltage electrocautery, otolaryngol. Otolaryngol Head Neck Surg. 116(3): 379-438. 